\title{
Promoting Students' Self-Regulated Learning Through Digital Platforms: New Horizon in Educational Psychology
}

\author{
Ahlem Chelghoum \\ Department of English, Faculty of Foreign Languages, University of Badji Mokhtar, Annaba, Algeria \\ Email address: \\ ahlemchelghoum@yahoo.fr \\ To cite this article: \\ Ahlem Chelghoum. Promoting Students' Self-Regulated Learning Through Digital Platforms: New Horizon in Educational Psychology. \\ American Journal of Applied Psychology. Vol. 6, No. 5, 2017, pp. 123-131. doi: 10.11648/j.ajap.20170605.17
}

Received: June 30, 2017; Accepted: July 25, 2017; Published: October 24, 2017

\begin{abstract}
In the last few decades, Information and Communication Technologies (ICTs) and Self-Regulation have become topics of prime interest in education. ICTs, for instance, are nowadays widely used in English as a foreign language (EFL) classes for being effective tools in facilitating teaching and learning. On the other hand, self-regulated learning is broadly demanded toemphasise students' autonomy and engagement in the learning process. With regard to educational psychology, self-regulated learning (SRL) has a notable effect on students' cognition, metacognition, motivation, and behaviours. However, in self-regulated learning, unlike self-directed learning, the teacher is primarily involved in the students' regulation practices. This creates a challenge to the teachers concerning their abilities to support self-regulation inside the classroom walls and in a limited time, especially with the rapid evolution of technology including online platforms. The major concern of this research paper lies in the ways that support students' self-regulation. Therefore, it ultimately discusses how online platforms, the case of 'Easyclass' can strengthen students' self-regulation skills in order to improve their achievement. It also tries to assist instructors in teaching students how to be effective self-regulated learners and promote their study skills and habits through technologies.
\end{abstract}

Keywords: ICT, Self-Regulated Learning, Motivation, Easyclass, Online Platforms, Educational Psychology

\section{Introduction}

In an era marked by the rapid growth of technology and the notable advances in educational psychology, education is undergoing vital changes that aim at fostering the learners' achievements. This is quite noticeable in learning languages, such as English. The latter is known as the language of communication or the global language for being widely used in the world. In other terms, learning English is the key to international communication. Nowadays, language teachers seek to develop their students' skills with regard to technology and psychology. Students in the $21^{\text {st }}$ century need to enhance not only skills related to speaking, listening, reading and writing, but also skills related to digital literacy, critical thinking, effective interaction and collaboration. In this respect, Chow states that the presence of technology in our life makes the full use of its tools a necessity in teaching and engaging the students [4]. He adds that teaching students who are highly connected with technology is a great challenge for nowadays' teachers who try to catch up with the continuous advances of technology and consider the traditional strategies of teaching [4]. In this digital world, it is necessary for the teachers, hence, to deeply understand the positive and negative effects of technology on education. Therefore, the teacher needs both knowledge and skills to captivate and, more importantly, motivate the $21^{\text {st }}$ century students [8]. The learners' motivation and achievement are closely intertwined. Motivation, which is one of the main teachers' concerns in education, can be raised by technology and promote lifelong learning in which the learners are more engaged in the classroom [2]. One of the challenging aspects this research tries to cast some light on is self-regulation. That is to be realised through the integration of online learning platforms in the classroom. Digital learning, particularly online platforms, have recently witnessed a central focus in education. Hence, the ultimate objective of this paper is to investigate to what extent online platforms can serve in developing students' self regulation. In other 
words, it tries to open up more possibilities for the learners to be more active in their education and learning, as well as to uncover students' willingness to learn with digital support.

\section{Educational Psychology}

Educational psychology is defined as the branch of psychology which is mainly related to the mental and behavioural processes of human learning. In other words, it focuses on understanding teaching and learning in education. The field of Educational Psychology is concerned with the nature of the learners and the characteristics of effective teaching. It involves the study of various phenomena such as memory, cognitive development, motivation, and self regulation [6]. Knowing more about the psychology of the learners in the classroom enables the teachers to develop the suitable ways and strategies of delivering instructions. This may be considered as the starting point to captivate the learners. Other researchers believe that educational psychology is the combination of two disciplines, which are education and psychology and, hence, define it as the knowledge obtained from the branch of psychology and applied to education [5] [9]. This highlights the connection between both fields which aims at improving students' academic success.

Nevertheless, contemporary educational psychology includes a broad and complex array of topics and practices. Nowadays, educational psychology is influenced by many multidisciplinary factors such as the incorporation of sociology, science, linguistics and psychology within educational systems [13]. This also leads to the use of technology in the classroom which has a major impact on education. This study endeavours to shed some light on the effects of technology, precisely, digital platforms on students' self regulation and academic performance.

\section{Self Regulated Learning}

Self regulation refers to the process of learning that is the results of students' cognitive control and their own achievements. It encompasses goal directed activities which allow the learners to actively engage in the learning practices rather than remain passive recipients of knowledge poured by their teachers [16]. SRL is the process that assists students in managing their thoughts, behaviours, and emotions in order to successfully navigate their learning experiences [16]. It enables the students to set their learning objectives to be successful learners. "New definitions of self-regulation (SR) embody all environmental, motivational, and meta-cognitive processes which result in quick academic success and achievement" [15]. According to Zimmerman, unlike passive learners, self regulated students seek out information when they face any hurdles such as confusing teachers, lack of information or the poor conditions of learning. He further adds that the major concepts of self regulation are meta-cognition, motivation and behaviours [20]. In this respect, a great number of definitions have been given to SRL related to numerous concepts such as self-control, self-management, behaviours, problem solving, meta-cognition, etc. [11]. Sardareh, Mohd Saad, and Boroomand claim that three major components of self regulation are very important, as far as the students' academic achievement is concerned [15]. The first component involves the meta-cognitive strategies used by the students in which they plan, set their objectives, selfmonitor, and organise their activities. The second component concerns the students' management in doing academic assignments. The third component of SRL is the use of cognitive strategies which enables the learners to understand and remember the different learned concepts used to learn, remember, and fully comprehend curricular concepts such as rehearsal, elaboration, and organisation [12] [15]. These elements can be controlled by the instructor through digital platforms. In other words, the learners will be exposed to the appropriate tools such as videos, quizzes, games, etc. which are chosen by the teacher and uploaded on the platform.

For instance, Zimmerman distinguishes between self regulation processes such as self-efficacy and the strategies used to mainly maximise these processes such as the purposes and the instruments set by the learners. In term of academic achievement, Zimmerman further states that SRL encompasses three main features: (a) the use of selfregulated learning strategies, (b) the responsiveness to selforiented feedback, and (c) the students' interdependent motivational processes [20]. Pintrich and De Groot believe that student engagement in SRL and students' efficacy beliefs about their performance and skills are highly correlated [12]. This correlation directs the learners towards the adequate learning strategies and raise their motivation to develop their academic scores, which is the purpose of many learners including the lazy or reluctant to learn ones.

\subsection{Theories of SRL}

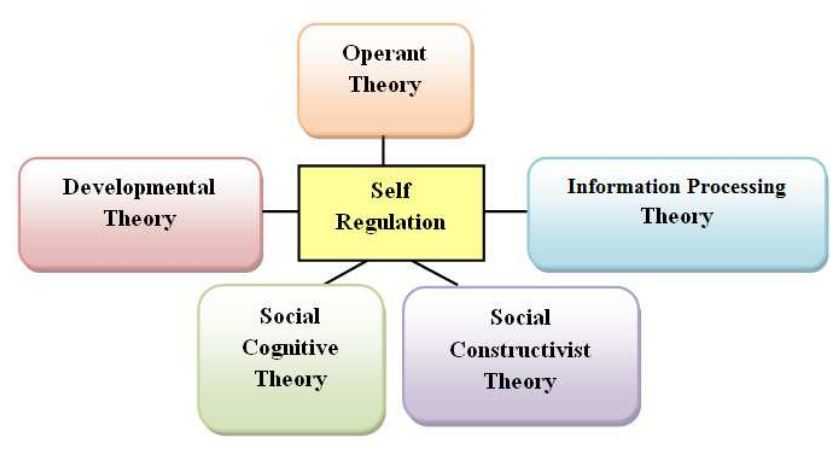

Figure 1. Theories of SRL, adopted from Schunk and Zimmerman [16].

Zimmerman first mentions five theoretical perspectives on self regulation (Figure 1). The first, the operant theory, is basically derived from the theories of Skinner (1953) and the use of stimuli to regulate behaviours. It involves three main features: self-monitoring, self-instruction, and selfreinforcement. The second is information processing theory, which is related to the encoding of information in long term 
memory. In this theory, the learners relate new information to their prior knowledge. In SRL, students' self-knowledge considers their interests, capacities and choosing adequate learning strategies to perform in different tasks [16]. The third, which is the developmental theory, concerns the cognitive aspects that assist the learners controlling their emotions, actions, and thoughts. The fourth theory, i.e. social constructivist theory, is highly related to cognitive development. It concerns the students' abilities to construct knowledge with regard to physical activities and social influence. It is also linked to Vygotsky theory (1962) who stressed out the importance of language in self regulation (ibid). The fifth theory of SRL is the social cognitive theory. This theory is applied by the learners in self-regulation depending on the situation, i.e. adopting specific processes of regulation in specific situations [16].

\subsection{Models of SRL}

In self-regulation, Zimmerman proposed a cyclical model which consists of three main phases: forethought, performance and reflection [19]. The three phases are summarised in the following table:

Table 1. Model of SRL [19].

\begin{tabular}{lll}
\hline \multirow{2}{*}{ Forethoughts } & Motivation & Personal beliefs, self-efficacy, goal orientation, etc. \\
& Cognitive & Goal setting \\
\multirow{3}{*}{ Performance } & Processes & Strategic planning \\
& Self-control & Self-talk, self-instruction \\
\multirow{2}{*}{ Reflection } & Self-observation & Self-monitory, time management, study skills \\
& Self-judgment & Self-evaluation \\
\hline
\end{tabular}

Winne, in his turn, proposed a model of SRL which consists of four main elements overlapping with Zimmerman's model. The First element is the understanding of the learning environment and task requirements i.e. defining the task. The second element is goal setting, in which the learners identify their aims and objectives in learning, while the third represents the ability of applying various strategies to achieve these objectives. The last element is adjusting strategies with regard to the different learning circumstances [18].

Johnson and Davies argue that both Zimmerman and Winne models complement each other. They highlight that the utmost components of SRL are: comprehension, pacification, strategies and evaluation (Figure 2) [10]. In order to enhance the learners' self-regulation, they should be aware of the four elements of SRL and how to apply these elements on various learning tasks. This represents one of the purposes of this study where the teacher provides the learners with the necessary explanation of SRL, their main components and how to apply them in their daily activities and objectives through online support.

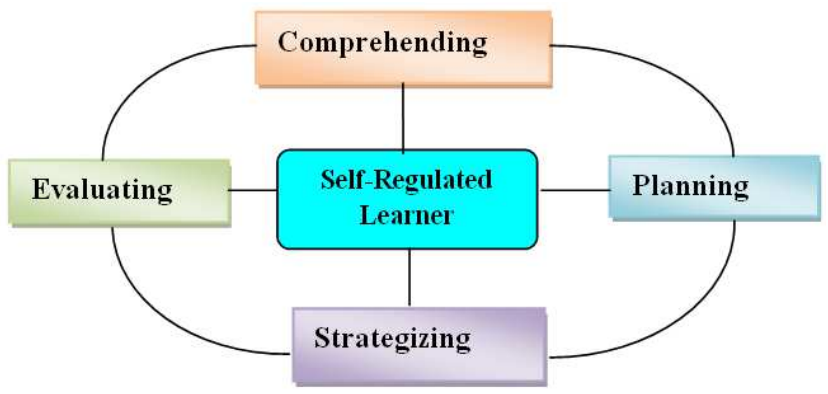

Figure 2. The cyclical cognitive processes of self-regulated Learning [10].

\section{Online Learning Platforms}

Over a decade ago, the massive advances in technology have affected both teachers and learners leading to a need for an up-to-date educational system that consider the $21^{\text {st }}$ century changes and the learners' expectations. Learning may take place inside and outside the classroom, with or without the teacher's instruction and within groups of learners or individually [3]. However, this study tries to encourage learning inside the classroom and cooperation in online settings. In other words, it attempts to develop learning and self-regulation via technology.

Digital platforms, for instance, are one of the popular technologies used in education. They are set to mainly support the learning/teaching process in online environments. They also aim at improving the learning activities and especially cater to the $21^{\text {st }}$ century learners. Technologies including educational software, digital learning tools, internet access, programmes and educational resources all play a significant role in education [1]. Online platform or learning management system (LMS) is a tool that enables the users to cooperatively work on virtual classrooms over several courses in higher education institutions [1]. These tools have a potential to enhance students' self-regulation due to their availability and flexibility [10]. Using digital devices in education provide the teachers with many facilities. They also foster the learners' motivation and enhance their academic achievement [17]. Some of these technologies are eportfolios, blogs and wikis, virtual environment, and PLE (Personal Learning Environment) [3]. Even so, for SRL and technology, some criteria need to be considered: (a) Encouraging learners to plan their learning activities, (b) providing them with appropriate feedback to monitor their learning, and (c) providing them with criteria of selfevaluation [3]. These elements represent the basic criteria of applying SRL in this study. Accordingly, using technology with SRL does not mean leaving the learners learn completely by their own. Through digital platforms, the 
learners can gain further knowledge of concepts taught in the classroom under the instructor guidance. They can develop their strategies of planning and organising their activities. This reflects on their achievement, motivation and self regulation.

\section{Method}

This study is intended to identify the effectiveness of online platforms in EFL classes and its effects on students' self-regulation. English as a Foreign Language (EFL) is getting increasingly a wide interest in many schools around the world. That is mainly for the sake of encouraging international communication. This makes teaching English fundamentally important in many countries in the world. Consequently, EFL teachers now need not only to focus on different aspects of learning a foreign language namely the four skills, grammar and vocabulary, but they also need to go beyond these aspects and reach the learners' interests to promote their learning experiences through self regulation.

\subsection{Subjects}

The selected sample of this study consists of 93 First year BA EFL students, University of Constantine, Algeria. The sample is divided into two groups in which one serves as the control group with 41 participants and the other as the experimental group with 52 participants. The participants of the experimental group joined an online platform called 'EasyClass' (Figure 3) to attend the English writing course. Concerning the gender difference, the overwhelming majority of the participants in the experimental group are females, $43(82.70 \%)$, while there are only 9 males $(17.31 \%)$. This is also the case with the control group in which 29 participants are females $(70.73 \%)$ and 12 are males $(29.27 \%)$. The gender split does not serve a lot to the purpose of this research work, but it remains an important factor in the classroom.

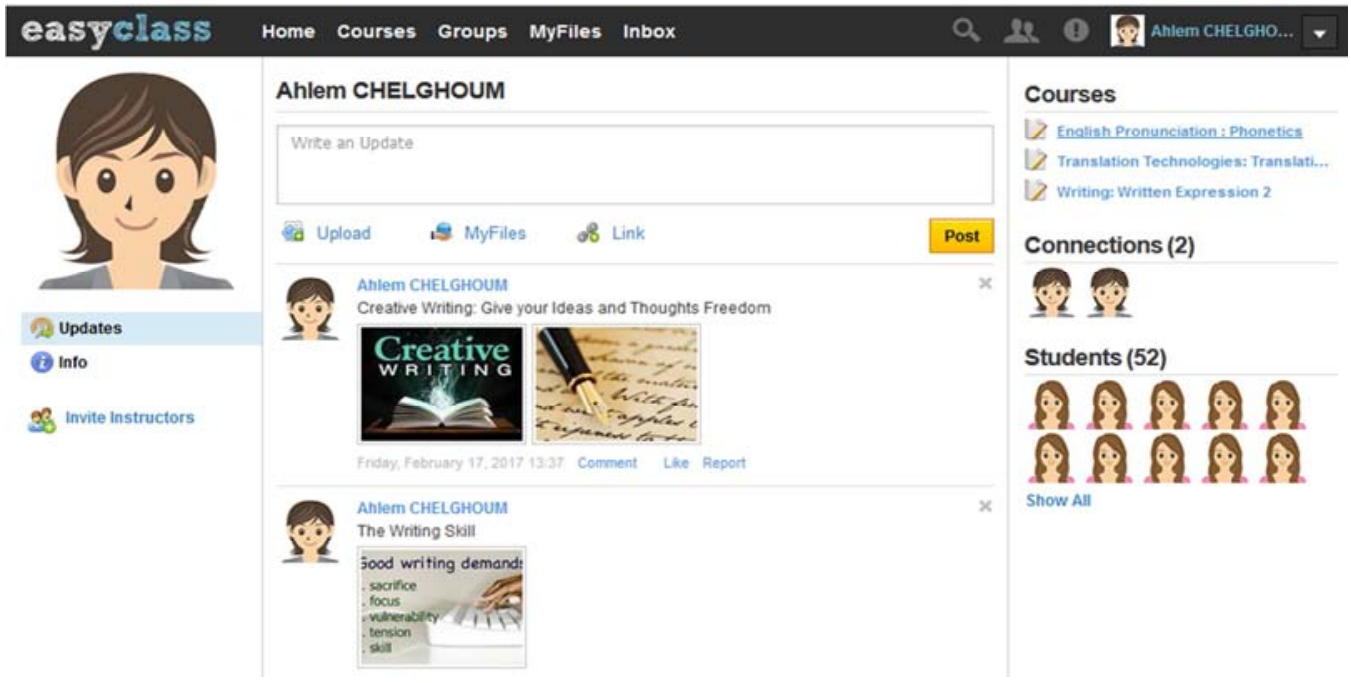

Figure 3. Screenshot of Easyclass Learning Platform.

\subsection{Research Tools}

\section{easyclass}

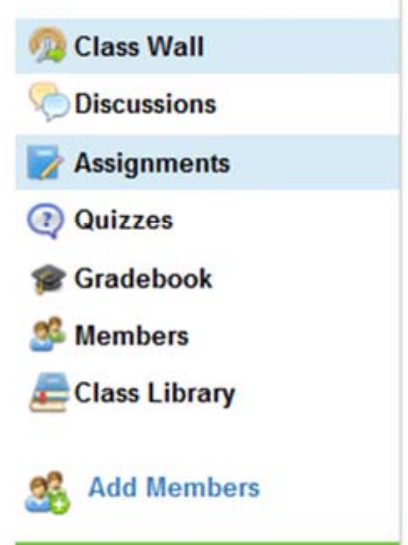

Figure 4. Components of Easyclass.
As previously stated, the tool used in this study is an online platform called 'Easyclass', which is an LMS that enables instructors to create virtual classrooms whereby they can give online lessons, assignments and quizzes. The components of the platform are shown in figure 4 . In order to develop the students' self regulation, Easyclass is used to assure a greater guidance of the students and provide them with better opportunities to rely on themselves. In other terms, Easyclass gives the teachers unique opportunities to engage their students in several activities outside the classroom walls. This helps them direct their students' self regulation and offer a significant dimension for more effective interactions. As previously specified, there are lots of technologies which show an influential role in education and particularly in developing the learners' performance, such as: interactive whiteboard, instructional videos, online games, and social media. Nonetheless, the choice is fallen on online platforms in this study for being simple and practical. Moreover, the involvement of the instructor in these tools 
boosts the teaching/learning process and prevents the learners from deep confusion. The latter may be due to the huge information offered in a variety of tools and media.

The assessment of the students' achievement in the experimental group was made by several online quizzes and assignments related to the writing course. The obtained results were compared to the students of the control group who were taught the same course without the integration of Easyclass. A questionnaire was also delivered to the students of the experimental group as an attempt to seek their point of

\section{Gradebook}

\begin{tabular}{|c|c|c|c|c|c|c|c|}
\hline \multirow{2}{*}{ Student Name } & \multicolumn{2}{|c|}{$\begin{array}{l}\text { Complete Sentence or } \\
\text { fragment }\end{array}$} & \multicolumn{2}{|c|}{ Phrase or clause } & \multirow[t]{2}{*}{ 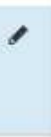 } & \multirow{2}{*}{$\begin{array}{c}\text { Final Grade } \\
\text { Max points } \\
100\end{array}$} & \multirow[b]{3}{*}{ ^ } \\
\hline & $\begin{array}{c}\text { Max points } \\
20\end{array}$ & $\begin{array}{l}\text { Weight } \\
14.3 \%\end{array}$ & $\begin{array}{l}\text { Max points } \\
20\end{array}$ & $\begin{array}{l}\text { Weight } \\
14.3 \%\end{array}$ & & & \\
\hline & 17 & 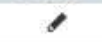 & 15 & 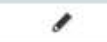 & & 63 & \\
\hline & 18 & 1 & 19 & 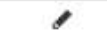 & & 82 & \\
\hline & 20 & 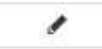 & 19 & 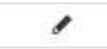 & & 84 & \\
\hline & 12 & $<$ & 10 & 6 & & 63 & \\
\hline & 18 & 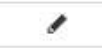 & 16 & 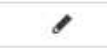 & & 67 & \\
\hline & 19 & 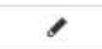 & 20 & 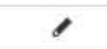 & & 76 & \\
\hline & 17 & 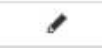 & 14 & 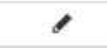 & & 72 & \\
\hline & 15 & ' & 15 & 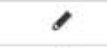 & & 70 & \\
\hline & 18 & 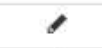 & 14 & 6 & & 71 & \\
\hline & 19 & 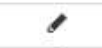 & 19 & 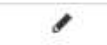 & & 80 & \\
\hline & 16 & 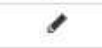 & 20 & 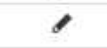 & & 87 & \\
\hline & 17 & $<$ & 15 & 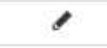 & & 80 & \\
\hline & 12 & 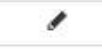 & 10 & 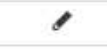 & & 65 & \\
\hline & 14 & 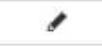 & 10 & 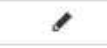 & & 58 & \\
\hline & 18 & $<$ & 14 & 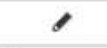 & & 68 & \\
\hline Average & \multicolumn{2}{|c|}{$17.4 / 20$} & \multicolumn{2}{|c|}{$15.9 / 20$} & & $70.1 / 100$ & \\
\hline Publish & \multicolumn{2}{|c|}{ Published } & \multicolumn{2}{|c|}{ Published } & & & $v$ \\
\hline
\end{tabular}

Figure 5. Screenshot of the Students' Gradebook in Easyclass (Experimental Group).
It can be noticed in this figure that only a part of the students' grades in the quizzes is shown. In this course, the students had seven quizzes (punctuation, types of sentences, wordiness, parallelism, etc), four assignments (writing paragraphs), and a project (create a school magazine). However, only the quizzes and writing narrative paragraphs were analysed for this research paper. In addition, the student names were removed from the table of grading. That is to provide completely anonymous results. view about the course, the digital platform, their motivational beliefs, self-regulation and self evaluation. The questionnaire was administered to the learners in which they answered the questions anonymously.

\section{Discussion of the Results}

The online learning platform, Easyclass, provides the instructors with a gradebook in which all the participants' obtained marks in the quizzes are displayed (Figure 5).

\section{Export Add New ltem}

\begin{tabular}{|c|c|c|c|}
\hline Student & Complete Sentence or Fragment (.../20) & Phrase or Clause $(\ldots / 20)$ & Final Grade $(. . . / 100)$ \\
\hline 1 & 7 & 10 & 40 \\
\hline 2 & 4 & 9 & 39 \\
\hline 3 & 16 & 17 & 76 \\
\hline 4 & 12 & 11 & 64 \\
\hline 5 & 9 & 7 & 51 \\
\hline 6 & 10 & 12 & 62 \\
\hline 7 & 12 & 8 & 45 \\
\hline 8 & 6 & 8 & 42 \\
\hline 9 & 9 & 13 & 50 \\
\hline 10 & 6 & 15 & 58 \\
\hline
\end{tabular}

As seen in the above table, the overall average of the
learners in the quizzes is $70.1 / 100$. This reveals the
improvement of the learners' skills in an online environment
compared to the results of the students of the control group.
The same quizzes that the students of the experimental
group had were given to the students of the control group in
a written form. Some of their results are displayed in the
following table:

As seen in the above table, the overall average of the
learners in the quizzes is $70.1 / 100$. This reveals the
improvement of the learners' skills in an online environment
compared to the results of the students of the control group.
The same quizzes that the students of the experimental
group had were given to the students of the control group in
a written form. Some of their results are displayed in the
following table:

As seen in the above table, the overall average of the
learners in the quizzes is $70.1 / 100$. This reveals the
improvement of the learners' skills in an online environment
compared to the results of the students of the control group.
The same quizzes that the students of the experimental
group had were given to the students of the control group in
a written form. Some of their results are displayed in the
following table:

As seen in the above table, the overall average of the
learners in the quizzes is $70.1 / 100$. This reveals the
improvement of the learners' skills in an online environment
compared to the results of the students of the control group.
The same quizzes that the students of the experimental
group had were given to the students of the control group in
a written form. Some of their results are displayed in the
following table:

As seen in the above table, the overall average of the
learners in the quizzes is $70.1 / 100$. This reveals the
improvement of the learners' skills in an online environment
compared to the results of the students of the control group.
The same quizzes that the students of the experimental
group had were given to the students of the control group in
a written form. Some of their results are displayed in the
following table:

As seen in the above table, the overall average of the
learners in the quizzes is $70.1 / 100$. This reveals the
improvement of the learners' skills in an online environment
compared to the results of the students of the control group.
The same quizzes that the students of the experimental
group had were given to the students of the control group in
a written form. Some of their results are displayed in the
following table:

As seen in the above table, the overall average of the
learners in the quizzes is $70.1 / 100$. This reveals the
improvement of the learners' skills in an online environment
compared to the results of the students of the control group.
The same quizzes that the students of the experimental
group had were given to the students of the control group in
a written form. Some of their results are displayed in the
following table: 
The overall average of the students of the control group in the quizzes is $46.3 / 100$. This reveals that the use of online course has an effect on the students' performance. Even though, a closer look at the students' results shows that there are some students who were able to get great scores in the control group, yet, the majority of students were below the average. Figure 6 shows the scores of 20 students from the control group obtained in two quizzes. The participants of the experimental group, on the other hand, were able to get, at least, the average in many quizzes. These results are due to several factors, but the integration of Easyclass is one of the most important factors that affected the students' marks (Figure 7).

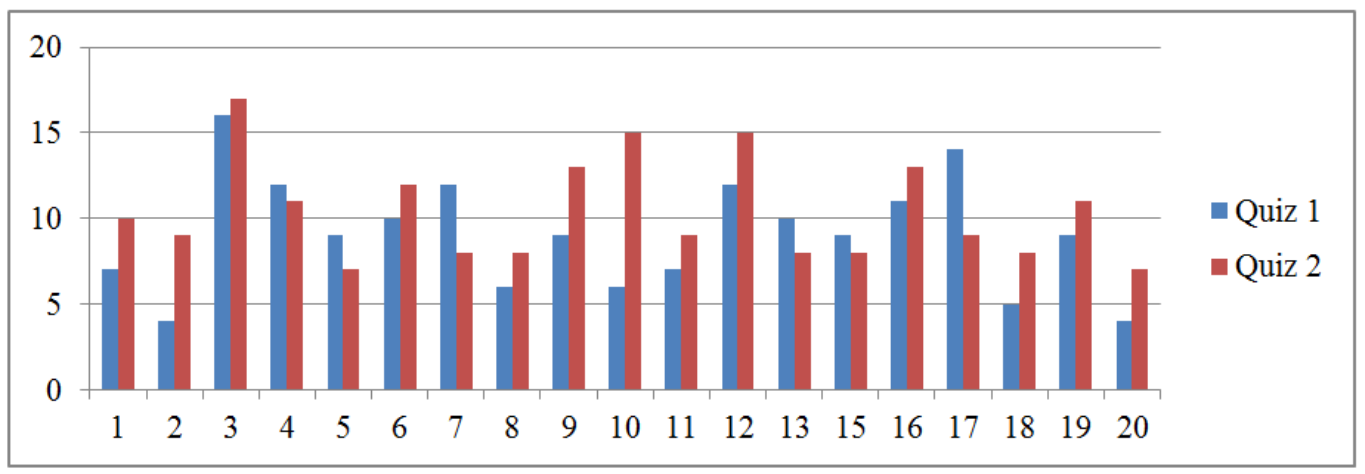

Figure 6. Students' Results in the Quizzes (Control Group).

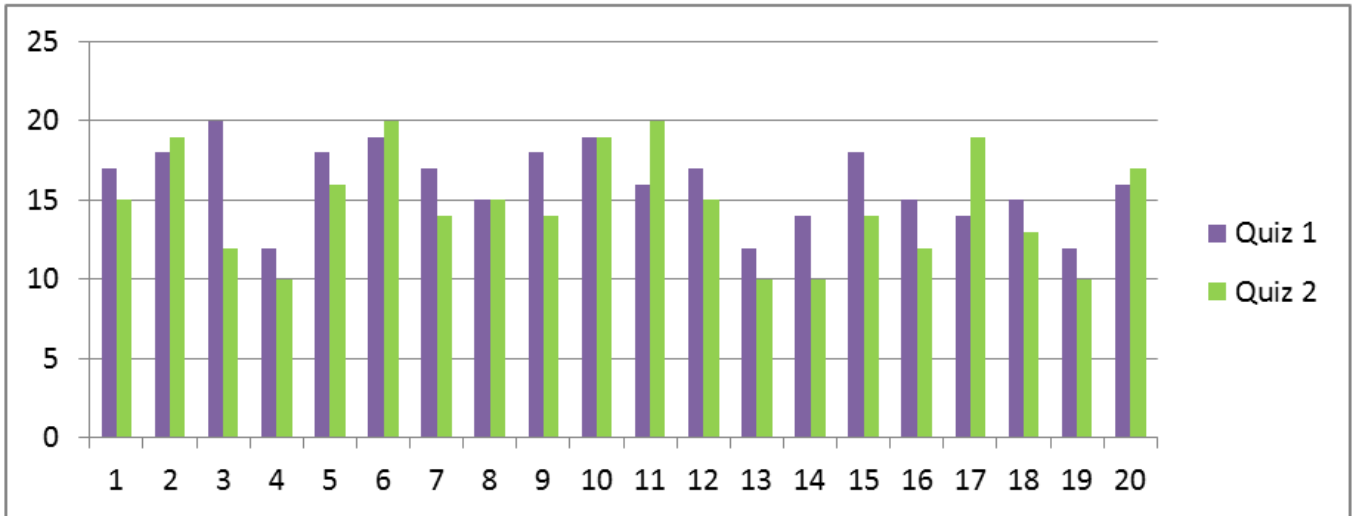

Figure 7. Students' Results in the Quizzes (Experimental Group).

Another assignment was given to both groups, in which they were asked to write a narrative paragraph about friendship. Both students had the same course concerning the characteristics and the stages of writing a narrative paragraph, etc. However, the students of the experimental group were able to see pictures and watch videos of songs and short stories about friendship on Easyclass in order to inspire them. They got also some opportunities to discuss the topic together in the discussion section (chat) on the same platform. The obtained results show that the paragraphs of the experimental group students were much better than those of the control group in matter of coherence, cohesion, and unity. Their pieces of writing were more organised and quality enhanced. On the other hand, the students of the control group provided paragraphs which lack unity. Many students tend to combine different ideas in one paragraph that are less related to the topic.

After a closer look, the main problems seen in the paragraphs of the control group students are: the misuse of transitions and pronouns, spelling mistakes, problems of punctuation and capitalisation and especially grammatical mistakes. However, students of the experimental group had problems of punctuation and some problems in the use of the appropriate tense. Examples of the students' mistakes in the assignment are shown in the following table:

Table 3. Examples of the Participants' Mistakes in the Writing Assignment.

\begin{tabular}{|c|c|}
\hline Students' Mistakes (Control Group) & Students' Mistakes (Experimental Group) \\
\hline $\begin{array}{l}\text { Frindship is very important for people it is very precious for us. } \\
\text { I knew my friend dalia when I were in school, she is my neighbor. }\end{array}$ & $\begin{array}{l}\text { She was sad very depressed and lonely sitting in the corner (punctuation). } \\
\text { I used to be bullied until one day, he came to rescue me and this is the } \\
\text { beginning of our friendship. }\end{array}$ \\
\hline $\begin{array}{l}\text { If you ask me about my friend adam i will say he is not my friend he is a } \\
\text { brother he is always with me he help me specialy in bad times (no } \\
\text { punctuation marks). }\end{array}$ & $\begin{array}{l}\text { I can not forget the day I first met Zahra. I was crying and she give me a } \\
\text { chocolate and smiled. }\end{array}$ \\
\hline
\end{tabular}


Thus, the major finding of this research is that the learners have enhanced their overall performance when they started working on Easyclass. With the teacher's continuous guidance and support, the learners have developed a sense of self-regulation. It is also quite noticeable that their motivation has significantly increased. This is determined by the teacher's observation of the students who became more interested in the course and more active compared to the students of the control group.
The analysis of the given questionnaire is set in order to check the validity of this claiming and investigate the students' attitudes towards digital learning. The questionnaire is divided into three sections: motivation, self regulation, and online learning platform. Table 4 displays the students' motivational beliefs. It reveals that the majority of the students are motivated in learning, and they like the integration of an online course into the classroom (blended learning).

Table 4. Students' Motivational Beliefs.

\begin{tabular}{lll}
\hline Question & Yes & No \\
\hline I expect to do very well in the class & $33(63.46 \%)$ & $19(36.54 \%)$ \\
I am a good student and I will get good grades & $21(40.38 \%)$ & $31(59.62 \%)$ \\
I like learning online & $41(90.38 \%)$ & $11(21.15 \%)$ \\
I learn from my mistakes & $39(75 \%)$ & $13(25 \%)$ \\
I have doubts about my abilities & $30(57.69 \%)$ & $22(42.31 \%)$ \\
\hline
\end{tabular}

A glance at the results shows that $63.46 \%$ of the participants are motivated to do well in their studies, and $40.38 \%$ of them are eager to get great marks in the subject. This even reduces the challenges of developing the learners' self-regulation. In the third question, the greatest majority of the participants stated that they like learning online. This may be explained by the evolution of technology in this era and students' interest in digital devices.

As seen from Table 5, the questions are set to seek students' self regulation. The results shown in this table reveal that the students have developed their skills and started using cognitive strategies in learning a subject. This positively affects the learners' overall performance in the course and the taken tests.

Table 5. Students' Self Regulation.

\begin{tabular}{|c|c|c|}
\hline Question & Yes & No \\
\hline When I study, I rely only on what the teacher said in the classroom & $27(51.92 \%)$ & $25(48.08 \%)$ \\
\hline When I study hard things, I keep on trying until I understand & $32(61.54 \%)$ & $20(38.46 \%)$ \\
\hline I am very nervous in the classroom & $20(38.46 \%)$ & $32(61.54 \%)$ \\
\hline When I study, I try to connect what I learn to things I already know & $28(53.85 \%)$ & $24(46.15 \%)$ \\
\hline When Istudy, I use various tools (books, internet, digital devices, etc.) & $50(96.15 \%)$ & $2(3.85 \%)$ \\
\hline When I study a new topic, I do my best to fully understand it & $33(63.46 \%)$ & $19(36.54 \%)$ \\
\hline
\end{tabular}

It is remarkable that the majority of the students use several tools when they study. They also do their best to understand new concepts and connect the new topics they learn to their prior knowledge.
The last section in the questionnaire concerns the students' attitudes towards the use of Easyclass as an online learning platform. The results are displayed in the following table:

Table 6. Students' Attitudes Towards Easyclass.

\begin{tabular}{|c|c|c|}
\hline Question & Yes & No \\
\hline I think learning through online platforms (Easyclass) is interesting & $49(94.23 \%)$ & $3(5.77 \%)$ \\
\hline I have understood the subject (Writing) better in online setting & $48(92.31 \%)$ & $4(7.69 \%)$ \\
\hline I use Easyclass to broaden my knowledge about different topics with my teacher and peers & $51(98.08 \%)$ & $1(1.92 \%)$ \\
\hline Easyclass helps me develop my skills and self-assessment. & $49(94.23 \%)$ & $3(5.77 \%)$ \\
\hline
\end{tabular}

A close look at Table 6 highlights the students' satisfaction about their level, skills and enjoyment after taking part in the online course. $94.23 \%$ of the learners stated that they have developed their skills through the platform, and they clearly indicated that learning online is worthy and interesting. The greatest part of the participants praised Easyclass for being an effective tool in raising their understanding of a subject. This is made through interaction and the availability of many resources under the instructor's observation. Considering the students' comments on the class wall of Easyclass, one may quickly assert that the greatest majority of the participants have positive attitudes towards the use of this platform in learning. A deep investigation into these comments shows that the students who gave positive remarks about the platform are the ones who got the best grades. Yet, few learners praised Easyclass even though their grades were just average. It is a stressful task to develop the students' self regulation, however, the integration of a digital platform into the classroom permits the teacher to be closer to the learner and, thus, guide them to be effective self-regulative learners. Setting learning objectives, motivation and self-control, deep understanding 
and the use of a variety of media uploaded by the instructor to the platform are all efficient ways to promote the students' self-regulated learning.

\section{Recommendations}

In the light of the obtained results, this research work recommends the use of technologies, particularly online learning platforms, in educational settings. That is ultimately to promote the learners self-regulation and, hence, optimise their performance in learning. Technology cannot replace the traditional teaching strategies, but it can support teaching at different levels. So, a proper integration of technology in the classroom will create a motivational and exciting atmosphere to the learners leading to success [7]. Gardner simply puts that the use of technology is only efficient provided that it attains the objectives of the course [7]. Aiming at improving the learners' self-regulation and enhancing their overall achievement, many technologies have shown effectiveness. However, the main concern of this study is to guide the learners' towards the efficient learning skills outside the classroom. This can be achieved through many online platforms, and Easyclass is one of them. The use of LMS plays a significant role in developing the teaching/learning process. It does not only serve in enhancing the learners' skills, but also facilitating the teacher's role as a guide inside and outside the classroom. Furthermore, the major findings of this research paper reveal the students' interest in learning online, which resulted in raising their motivation. It is highly believed that motivation represents the key to successful academic achievement and life-long learning [14]. So, triggering the learners' interest through the integration of several technologies is very effective, especially with learners who have grown up surrounded by all types of technologies which are embedded into almost everything they do in their daily life. LMS also increases the learner-teacher and learner-learner interactions which has the potential to improve the students' sense of collaboration and reduce the levels of anxiety.

\section{Conclusion}

The current paper concludes that promoting the students' cognitive strategies of self regulation can be realised in online environments, especially with the latest advances in technology and the massive widespread use of digital devices in education. According to the previously stated findings, this research comes up with implications in favour of the integration of technology in educational psychology in order to support both teachers and learners. It endeavours to maximise the students' level by encouraging them to be more engaged in the learning activities. In other terms, teachers may promote students' academic achievement, motivation and life-long learning via online learning platforms as a medium of connection with their students. This enables the teachers to teach their students to be more self regulative without the limits of time and space.

\section{References}

[1] Abdul Kadir, A. Z., \& Aziz, N. S. (2016). Learning Management System of Higher Education Institution. Indian Journal of Science and Technology, 9 (9), 1-5.

[2] Beeland, W. (2002). Student engagement, visual learning and technology: can interactive whiteboards help? Retrieved June 2017, from

http://downloads01.smarttech.com/media/research/internation al_research/usa/beeland_am.pdf

[3] Carneiro, R., Lefrere, P., Steffens, K., \& Underwood, J. (Eds.). (2011). Self-Regulated Learning in Technology Enhanced Learning Environments (Vol. 5). Rotterdam / Boston / Taipei: Sense Publishers.

[4] Chow, P. (2015, April). Teachers Attitudes Towards Technology in the Classroom. Master of Teaching Dissertation, Ontario Institute for Studies in Education of the University of Toronto.

[5] Clifford, M. M. (1984). Educational Psychology. InEncyclopedia of Education (pp. 413-416). New York: MacMilan.

[6] Fetsco, T., \& McClure, J. (2005). Educational Psychology: An Integrated Approach To Classroom Decisions. Boston: Pearson.

[7] Gardner, C. J. (2011, April 12). Retrieved June 2017, at http://www.jclarkgardner.com/uploads/5/4/1/4/5414483/jclark _gardner_learning_motivation_2.pdf

[8] Granito, M., \& Chernobilsky, E. (2012). The Effect of Technology on a Student's Motivation and Knowledge Retention. (17).

[9] Grinder, R. E. (1981). The New Science of Education: Educational Psychology in Search of a Mission. In F. H. Farley, \& N. J. Gordon (Eds.), Psychology and Education: The State of the Union. Berkeley CA: McCutchan.

[10] Johnson, G. M., \& Davies, S. M. (2014). Self-Regulated Learning in Digital Environments: Theory, Research, Praxis. British Journal of Research, 68-80.

[11] Martin, J., \& McLellan, A.-M. (2007). The Educational Psychology of Self-Regulation: A Conceptual and Critical Analysis. Studies in Philosophy and Education (27), 433448.

[12] Pintrich, P. R., \& De Groot, E. V. (1990). Motivational and Self-Regulated Learning Components of Classroom Academic Performance. Journal of Educational Psychology, 82 (1), 33-40.

[13] Reynolds, W. M., \& Miller, G. E. (Eds.). (2003). Handbook of Psychology: Educational Psychology (Vol. VII). New Jersey.: John Wiley \& Sons, Inc.

[14] Sanacore, J. (2008). Turning Reluctant Learners into Inspired Learners. Clearing House: A Journal of Educational Strategies, Issues and Ideas, 81 (1), 40-44.

[15] Sardareh, S. A., Mohd Saad, M. R., \& Boroomand, R. (2012). Self-Regulated Learning Strategies (SRLS) and academic achievement in pre-university EFL learners. California Linguistic Notes, XXXVII (1), 1-35. 
[16] Schunk, D. H., \& Zimmerman, B. J. (2003). Self-Regulation and Learning. In W. M. Reynolds, \& G. E. Miller (Eds.), Handbook of Psychology: Educational Psychology (Vol. VII, pp. 59-78). New Jersy: John Wiley \& Sons, Inc.

[17] Thuseethan, S., \& Kuhanesan, S. (2014). Effective Use of Human Computer Interaction in Digital Academic Supportive Devices. International Journal of Science and Research, 3 (6), 388-392.
[18] Winne, P. H. (2005). Key Issues in Modelling and Applying Research on Self-Regulated Leanring. Applied Psychology, 54 (2), 232-238.

[19] Zimmerman, B. J. (2002). Becoming a Self-Regulated Learner: An Overview. Theory into Practice, 41 (2), 64-70.

[20] Zimmerman, B. J. (1990). Self-Regulated Learning and Academic Achievement: An Overview. Educational Psychologist, 25 (1), 3-17. 